\title{
Dynamic behaviour of HPFRCC in tension
}

\author{
E. Cadoni ${ }^{1}$, A. Caverzani ${ }^{2}$, and M. di Priscoi ${ }^{2}$ \\ ${ }^{1}$ DynaMat Lab., University of Applied Sciences of Southern Switzerland, 6952 Canobbio, Switzerland \\ ${ }^{2}$ Structural Engineering Dept., Politecnico di Milano, 20133 Milan, Italy
}

\begin{abstract}
High Performance Fiber Reinforced Cementitious Composites belong to a new class of structural materials characterized by high strength and ductility. Thanks to the high energy absorbed during the fracture process, due to multiple cracking and pull-out phenomena, they are often suggested for dynamic loading applications. Current understanding of the dynamic response is very limited because of very few investigations have been actually carried out. An experimental research aimed at contributing to the understanding of the behaviour of advanced fiber-reinforced cementitious composites subjected to low and high strain rates was carried out. The material investigated is a High Performance Fiber Reinforced Cementitious Composites. Straight high carbon steel micro-fibers were used. The material behaviour was investigated at several strain rates and the tests results were compared with their static behaviour. Tests at intermediate strain rates were carried out by means of a hydro-pneumatic machine (HPM), while high strain rates were investigated by exploiting a Split Hopkinson Tensile Bar (SHTB). A comparison between static and dynamic tests highlighted several relevant aspects regarding the influence of fibers on the peak strength and post-peak behaviour at high strain rates. Finally, this material will be employed in the construction of an innovative tunnel segment designed for extreme conditions (high temperature and shock).
\end{abstract}

\section{Introduction}

The use of High Fiber Reinforced Cementitious Composite (HFRCC) has been continuously increasing during the last years because of its enhanced performance in terms of toughness and crack control. HFRCC is now widely used is construction industry as in refurbishing or in segmental tunnels $[1,2]$.

The growing interest in applying HPFRCC in the field of structural engineering has point out the necessity of better knowing its behaviour under dynamic loading cases. In fact they are often used to improve impact and blast resistance due to their ability in energy absorption.

Unfortunately, scanty information are available, consequently more efforts should be addressed to analyse the mechanical properties in a wide range of strain and stressrate.

As mentioned one of the more promising application is in tunnelling because exceptional events can occur, even if characterized by a low occurrence probability, but they can involve very severe damage level on structure and people. Recent serious accidents occurred in roadway tunnels, like the tragedies of Mont Blanc Tunnel (March 1999) or Gotthard tunnel (October 2001), with serious human losses and hard economical problems. These had shown as explosions and fires in tunnels are definitely an essential safety issues. Considering that Italy is the European country with the highest number of roadway tunnels with length over 500 meters and Switzerland is an alpine state with a high density of tunnels with respect to its surface, the tunnel safety is a crucial aspect that needs further improvements.

In this framework, a project founded by INTERREG, a special cohesion program between Italy and Switzerland supported by the European Commission and the Swiss Confederation, and named ACCIDENT (Advanced Cementitious Composites In DEsign and coNstruction of safe Tunnel) is inserted [3]. The two project leaders are the
Politecnico di Milano- Polo Regionale di Lecco (LeccoItaly) and the University of Applied Sciences of Southern Switzerland (Lugano-Switzerland); the other subjects are nine industrial and institutional partners (3 Swiss and 6 Italian). The project is addressed in particular to develop new tunnel segments (see figure 1), designed by using advanced structural materials as HPFRCC. The constitutive laws represent the basic knowledge for the structure design, oriented to the manufacturing of new products for tunnels, trying to increase safety in accidents where fire and blast cause permanent damage or obstacle the first aid, due to partial collapse.

In the present paper, results from an experimental program focused on the dynamic behaviour of HPFRCC in tension are described. Tests at intermediate strain rates were carried out by means of a hydro-pneumatic machine (HPM), while high strain rates were investigated by exploiting a Split Hopkinson Tension Bar. A comparison between static and dynamic tests highlighted several relevant aspects regarding the influence of fibers on the peak strength and post-peak behaviour at high strain rates.

\section{Materials}

The mix design of the HPFRCC self compacting material is specified in Table 1. Steel fibres are high carbon straight fibres, $13 \mathrm{~mm}$ long, with a $0.16 \mathrm{~mm}$ diameter; their content is equal to $100 \mathrm{~kg} / \mathrm{m}^{3}$ [4]. Manufacturing process was composed by more phases. First of all a $30 \mathrm{~mm}$ thick slab $1.6 \mathrm{~m} \times 0.60 \mathrm{~m}$ in plane was cast. The casting was carried out by applying a unidirectional flow in order to guarantee a certain fibre orientation.

Twelve prismatic samples, $40 \mathrm{~mm}$ wide and $600 \mathrm{~mm}$ long, were sawed from the slab taking the larger side of beams parallel to the casting flow direction. Three specimens were tested in bending at room temperature and 
Table 1. Mix composition.

\begin{tabular}{|l|c|}
\hline & Dosage $\left(\mathbf{k g} / \mathbf{m}^{3}\right)$ \\
\hline Cement type I 52.5 & 600 \\
\hline Slag & 500 \\
\hline Water & 200 \\
\hline Super plasticizer & $33\left(1 / \mathrm{m}^{3}\right)$ \\
\hline Sand 0-2 $\mathrm{mm}$ & 983 \\
\hline Fibres $\left(\mathrm{l}_{\mathrm{f}}=13 \mathrm{~mm} ; \mathrm{d}_{\mathrm{f}}=0.16 \mathrm{~mm}\right)$ & 100 \\
\hline
\end{tabular}

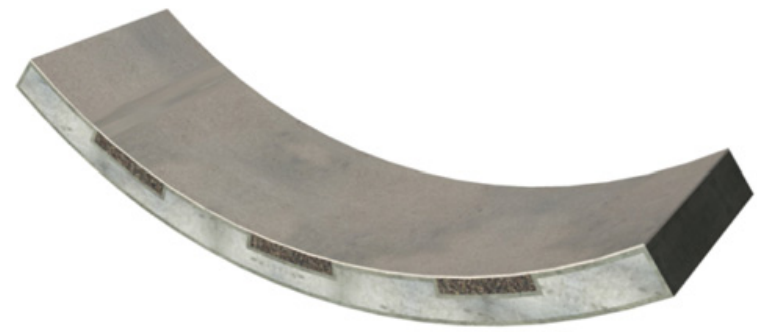

Fig. 1. Tunnel segment made with new class of structural materials for extreme conditions (high temperature and shock).

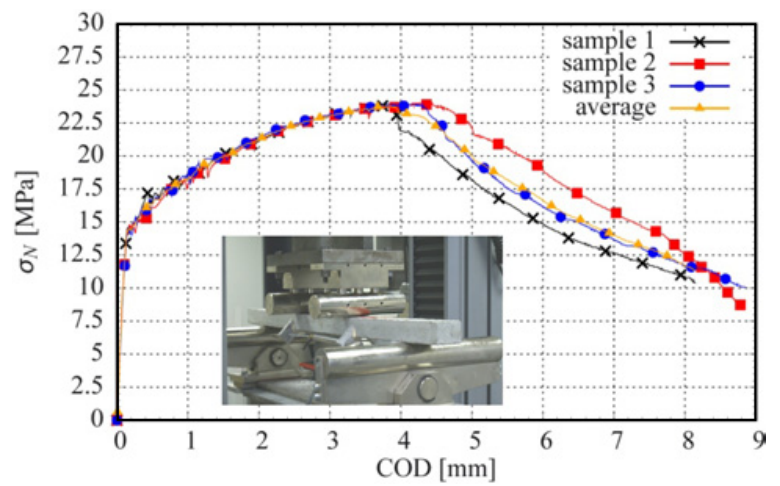

Fig. 2. Results of bending test [5].

in figure 2 the stress versus crack opening displacement (COD) curves are shown [5].

From the bent specimens, several small cylinders, objects of the present work, were cored in the direction of tensile stresses to be tested in uniaxial tension at different loading rates.

\section{Experimental set-up}

\subsection{Quasi static test}

Uniaxial tension tests were carried out on notched $20 \mathrm{~mm}$ high cylinders with a $20 \mathrm{~mm}$ diameter (notch depth $=$ $1.5 \mathrm{~mm}$ ), glued to the press platens by means of an epoxy resin. Two aluminium cylinders connected to the press by means a knuckle joint (figure 3 ) were used as press platens. In both cylinders a $5 \mathrm{~mm}$ deep cylindrical cavity with a $22 \mathrm{~mm}$ diameter was made in order to increase the glued sample surface. The tests were carried out by means of a closed loop electro-mechanical press INSTRON 5867

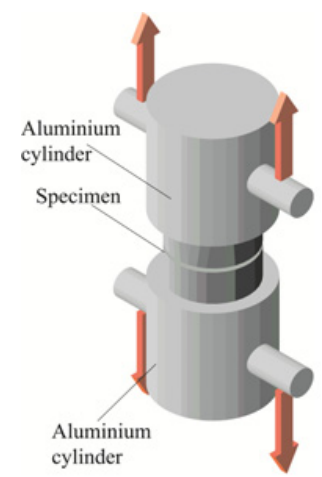

Fig. 3. Set-up for quasi-static test.

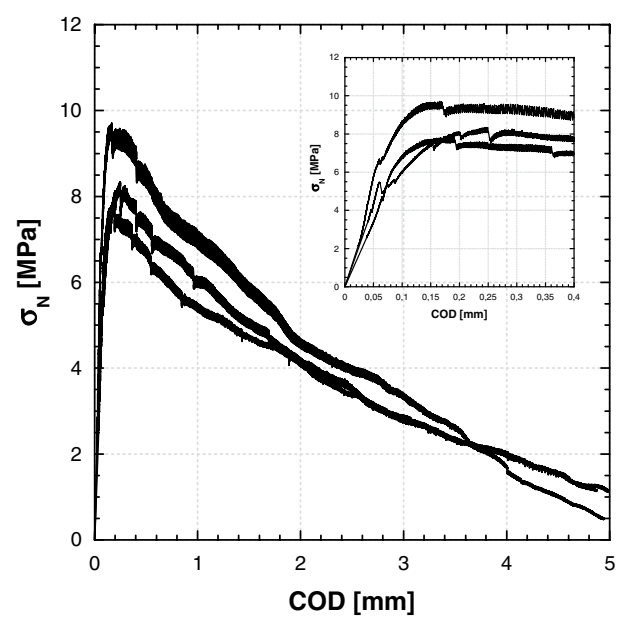

Fig. 4. Quasi-static test results of the HPFRCC.

with the maximum load capacity equal to $30 \mathrm{kN}$. Stroke was considered as feedback parameter during the tests. The displacement rate imposed during the tests was equal to $5.0 \times 10^{-5} \mathrm{~mm} / \mathrm{s}$ up to $1.5 \mathrm{~mm}$ and after progressively increased to $10^{-3} \mathrm{~mm} / \mathrm{s}$.

The results of tensile tests are shown in figure 4 in terms of nominal stress $\left(\sigma_{\mathrm{N}}\right)$ versus crack opening displacement (COD). In figure 4 a detail of the peaks zone is plotted in order to highlight the first linear elastic and post peak behaviour close to the peak. The prepeak behaviour is well described by a parabola-rectangular model, where the plateau is very close to a value of about $2 \%$.

Peak strengths and corresponding crack opening displacements $\left(\mathrm{w}_{\text {peak }}\right)$ are listed in Table 2; the values of peak strains reported in Table 2 were calculated as it follows:

$$
\varepsilon_{\text {peak }}=w_{\text {peak }} / \mathrm{L}^{*}
$$

where $L^{*}$, the clear spam $(=10 \mathrm{~mm})$, represents the equivalent specimen length [4].

On the basis of presented results it is possible to compute the total energy absorbed by the specimen during the test up to the reaching of a negligible stress transmitted by fibres $\left(G_{f}\right.$; Table 2$) . G_{f}$ represents the fracture energy computed as the subtended area in a stress - COD curve (see eq. (2)).

$$
G_{f}(C O D)=\int_{0}^{C O D} \sigma_{N}(x) d x
$$


Table 2. Quasi static results.

\begin{tabular}{lccccc}
\hline Sample & $\begin{array}{c}\mathrm{W}_{\text {peak }} \\
{[\mathrm{mm}]}\end{array}$ & $\begin{array}{c}\sigma_{\text {peak }} \\
{[\mathrm{MPa}]}\end{array}$ & $\begin{array}{c}\text { fiber } \\
\mathrm{n}^{\circ}\end{array}$ & $\begin{array}{c}\varepsilon_{\text {peak }}= \\
\mathrm{w}_{\text {peak }} / \mathrm{L}^{*}\end{array}$ & $\begin{array}{c}G_{f} \\
{\left[\mathrm{~kJ} / \mathrm{m}^{2}\right]}\end{array}$ \\
\hline 1 & 0.17 & 9.71 & 75 & $1.70 \mathrm{E}-02$ & 21.22 \\
\hline 2 & 0.19 & 7.83 & 73 & $1.90 \mathrm{E}-02$ & 18.11 \\
\hline 3 & 0.25 & 8.33 & 77 & $2.46 \mathrm{E}-02$ & 19.19 \\
\hline
\end{tabular}

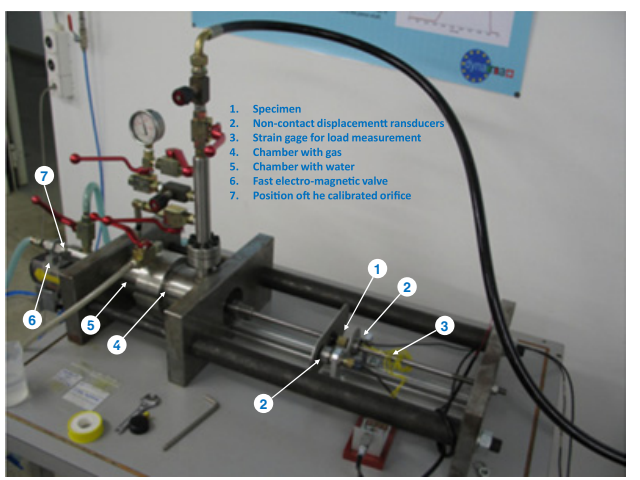

Fig. 5. Hydro-Pneumatic Machine for intermediate strain rate testing.

In order to study the influence of the fibre on the tension behaviour also the strength of the matrix (HPCC) has measured by quasi-static tests obtaining an average value of $\mathrm{s}_{\text {peak }}=6.15 \mathrm{MPa}$.

\subsection{Intermediate strain rate test}

A hydro-pneumatic machine (HPM) was employed to investigate the intermediate strain rate.

The HPM (see figure 5) functioning is widely described in [6], here only a briefly description of the device is reported. At the beginning of the test, a sealed piston divides the cylindrical tank into two chambers, one being filled with gas at high pressure (viz. 150 bars), and the other with water. An equal pressure is initially established in the water and gas chambers so that the forces acting on the two faces of the piston are in equilibrium. The test starts when the second chamber discharges the water through a calibrated orifice that is activated by a fast electro-valve. The piston starts then to move, expelling the water. The specimen is connected on one side to the piston shaft and, on the other side, to the end of an elastic bar which is rigidly fixed to a supporting structure. The elastic bar is instrumented with a strain-gauge that provides, through the elastic properties of the bar, the force acting on the specimen during the test. Two targets are attached at both ends of the specimen and their movement is measured by two contactless displacement transducers.

\subsection{High strain rate test}

The study of the behavior of the HPFRCC at high strain rate was performed using a Split Hopkinson Tensile Bar (SHTB) [4-6] installed in the DynaMat laboratory of the
Table 3. Intermediate strain rate results.

\begin{tabular}{lccccc}
\hline $\begin{array}{l}\text { Material } \\
\text { type }\end{array}$ & $\begin{array}{c}\text { Strain } \\
\text { rate } \\
{\left[\mathrm{s}^{-1}\right]}\end{array}$ & $\begin{array}{c}\text { Fibers } \\
\mathrm{n}^{\circ}\end{array}$ & $\begin{array}{c}\mathrm{w}_{\text {peak }} \\
{[\mathrm{mm}]}\end{array}$ & $\begin{array}{c}\sigma_{\text {peak }} \\
{[\mathrm{MPa}]}\end{array}$ & $\begin{array}{c}\sigma_{\text {peak,ave }} \\
{[\mathrm{MPa}]} \\
(\mathrm{std})\end{array}$ \\
\hline HPFRCC & 0.1 & 71 & 0.38 & 13.07 & \\
& & 76 & 0.57 & 10.30 & 12.36 \\
& & 72 & 0.53 & 13.71 & $(1.81)$ \\
\hline HPCC & 0.1 & - & 0.17 & 10.54 & \\
& & - & 0.35 & 7.87 & 9.12 \\
& & - & 0.12 & 8.95 & $(1.34)$ \\
\hline & 1 & 76 & 0.37 & 14.29 & \\
HPFRCC & & 71 & 0.46 & 14.09 & 15.25 \\
& & 73 & 0.81 & 17.67 & $(1.65)$ \\
HPCC & 1 & - & 0.10 & 10.22 & \\
& & - & 0.51 & 11.33 & 11.31 \\
& & - & 0.27 & 12.36 & $(1.07)$ \\
\hline
\end{tabular}

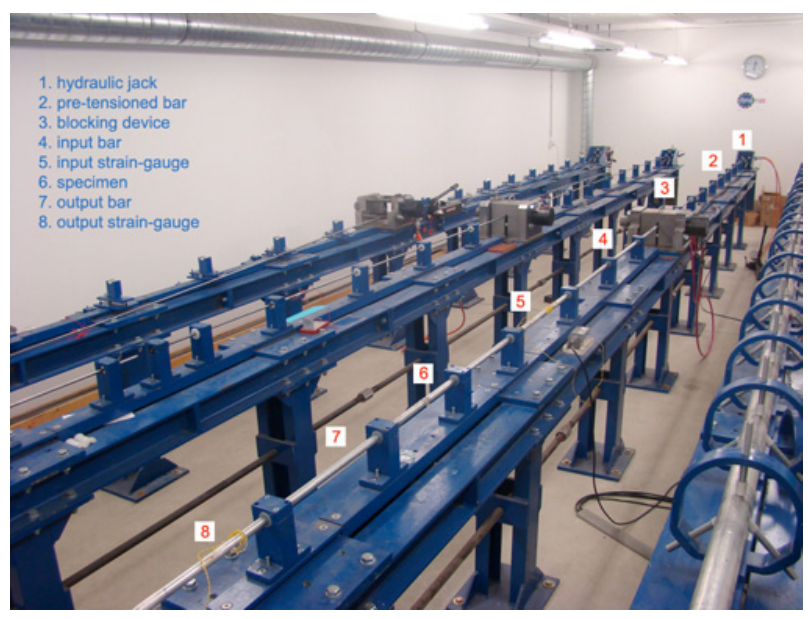

Fig. 6. Split Hopkinson Tension Bar.

University of Applied Sciences of Southern Switzerland (SUPSI) of Lugano (figure 6).

The machine consists of two $20 \mathrm{~mm}$ diameter aluminum half-bars (the input and output bar respectively), with the specimen sandwiched in between. By pulling one end (the other is connected with a blocking system) of the high strength steel bar having a length of $6 \mathrm{~m}$ and a diameter of $12 \mathrm{~mm}$ (named pre-tensioned bar), elastic energy is stored in the pre-tensioned bar, which is connected with the incident bar. The diameter of the pre-tensioned bar has been chosen in order to have a better matching of the acoustical impedance with the input bar.

By releasing this energy (rupturing the brittle intermediate piece), a rectangular shape wave (with $2.4 \mathrm{~ms}$ duration) with small rise-time $(30 \mu \mathrm{s})$ is generated and transmitted along the input bar loading the specimen to failure. This is a uniaxial elastic plane stress wave, as the wave-length of the pulse is long compared to the bar transverse dimensions, and the pulse amplitude does not exceed the yield strength of the bar.

The pulse propagates along the input bar with the velocity $\mathrm{C}_{0}$ of the elastic wave with its shape remaining constant. When the incident pulse $\left(\varepsilon_{\mathrm{I}}\right)$ reaches the 


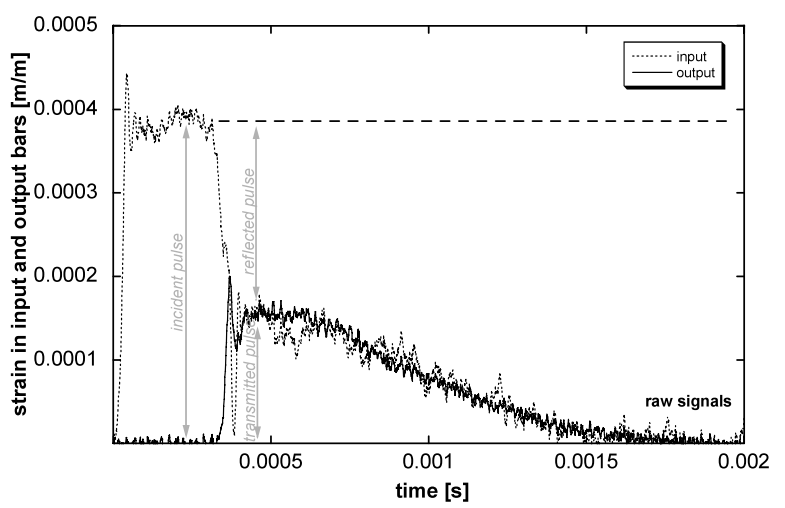

Fig. 7. Raw signals obtained from SHTB.

HPFRCC specimen, part of it $\left(\varepsilon_{\mathrm{R}}\right)$ is reflected by the specimen whereas another part $\left(\varepsilon_{\mathrm{T}}\right)$ passes through the specimen propagating into the output bar as shown in figure 6 . The relative amplitudes of the incident, reflected and transmitted pulses, depend on the mechanical properties of the specimen. Strain-gauges glued on the input and output bars of the device are used for the measurement of the elastic deformation (as a function of time) created on both half-bars by the incident/reflected and transmitted pulses, respectively.

In figure 7 the raw signals measured on the input and output bars are shown. It can be observed the clean resolution of incident, reflected and transmitted pulses, the sharp rise time of the incident pulse of the order of $30 \mu \mathrm{s}$, and the nearby constant amplitude of the incident pulse. Moreover during the fracture process the specimen is subjected to the load equilibrium, because the signals $\left(\varepsilon_{\mathrm{I}}+\varepsilon_{\mathrm{R}}\right)$ and $\varepsilon_{\mathrm{T}}$ are equal. In fact, naming $\mathrm{F}_{1}$ the load in the specimen-input bar interface and $\mathrm{F}_{2}$ the load in the specimen-output interface they are defined as: $\mathrm{F}_{1}(\mathrm{t})=\mathrm{A}_{0}$ $\mathrm{E}_{0}\left(\varepsilon_{\mathrm{I}}+\varepsilon_{\mathrm{R}}\right)$ and $\mathrm{F}_{2}(\mathrm{t})=\mathrm{A}_{0} \mathrm{E}_{0} \varepsilon_{\mathrm{T}}$.

By using the theory of the elastic wave propagation in bars, and the well substantiated assumption of specimen equilibrium attainment, the stress and strain in the specimen as well as the history of the crack opening displacement (COD) and the strain-rate can be calculated $[4,6,7]$ :

$$
\begin{gathered}
\sigma(\mathrm{t})=\mathrm{E}_{0} \frac{A_{0}}{\mathrm{~A}} \varepsilon_{\mathrm{T}}(\mathrm{t}) \\
\varepsilon(\mathrm{t})=-\frac{2 \cdot \mathrm{C}_{0}}{\mathrm{~L}} \int_{0}^{\mathrm{t}} \varepsilon_{\mathrm{R}}(\mathrm{t}) \mathrm{dt} \\
\mathrm{COD}(\mathrm{t})=-2 \cdot \mathrm{C}_{0} \int_{0}^{\mathrm{t}} \varepsilon_{\mathrm{R}}(\mathrm{t}) \mathrm{dt} \\
\dot{\varepsilon}(\mathrm{t})=-\frac{2 \cdot \mathrm{C}_{0}}{\mathrm{~L}} \varepsilon_{\mathrm{R}}(\mathrm{t})
\end{gathered}
$$

where: $\mathrm{E}_{0}$ is the elastic modulus of the bars; $\mathrm{A}_{0}$ their crosssectional area; $\mathrm{A}$ is the specimen cross section area; $\mathrm{L}$ is the specimen gauge length; $\mathrm{C}_{0}$ is the sound velocity of the bar material; $\mathrm{t}$ is time.

The results at high strain rate are reported in table 4 and in figure 8 .
Table 4. High strain rate results.

\begin{tabular}{lccccc}
\hline $\begin{array}{l}\text { Material } \\
\text { type }\end{array}$ & $\begin{array}{c}\text { Strain } \\
\text { rate } \\
{\left[\mathrm{s}^{-1}\right]}\end{array}$ & $\begin{array}{c}\text { Fibers } \\
\mathrm{n}^{\circ}\end{array}$ & $\begin{array}{c}\mathrm{w}_{\text {peak }} \\
{[\mathrm{mm}]}\end{array}$ & $\begin{array}{c}\sigma_{\text {peak }} \\
{[\mathrm{MPa}]}\end{array}$ & $\begin{array}{c}\sigma_{\text {peak,ave }} \\
{[\mathrm{MPa}]} \\
(\mathrm{std})\end{array}$ \\
\hline \multirow{3}{*}{ HPFRCC } & 150 & 79 & 0.038 & 20.46 & \\
& & 90 & 0.032 & 22.28 & 22.36 \\
& & 79 & 0.024 & 24.96 & $(1.89)$ \\
HPCC & 150 & - & 0.008 & 15.89 & \\
& & - & 0.020 & 18.48 & 17.05 \\
& & - & 0.010 & 16.77 & $(1.32)$ \\
\hline
\end{tabular}

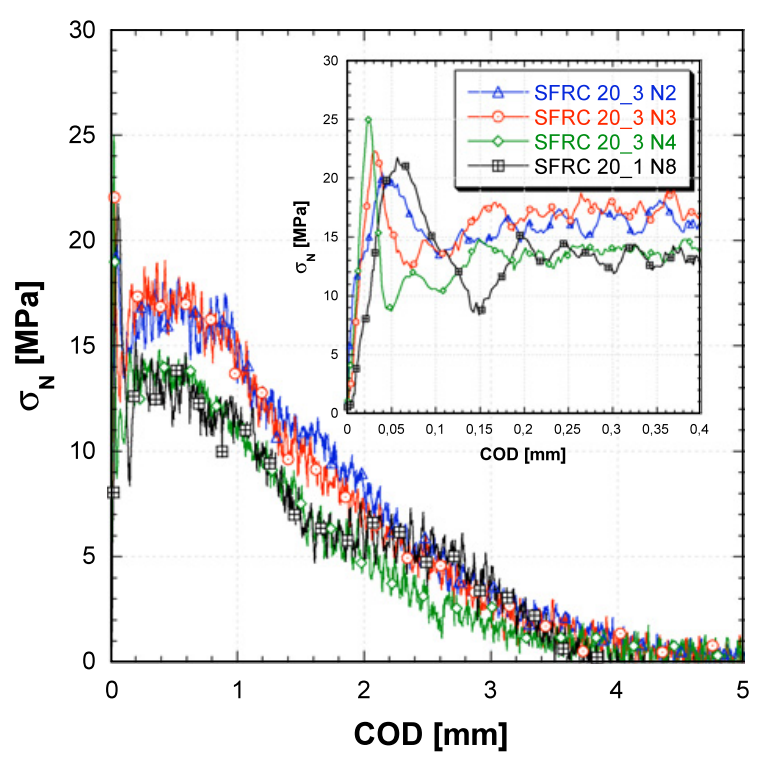

Fig. 8. High strain rate test results of the HPFRCC.

\section{Analysis of the results}

The strain rate behaviour of the HPFRCC can be described by the increment of the strength from quasi static and dynamic conditions. Usually this ratio is named Dynamic Increase Factor (DIF) and for plain concrete several formulation have been proposed [4]. Because of scanty of experimental data on HPFRCC at the moment no expression is actually recommended. In this paper the comparison between the HPFRCC and HPCC is done. Taking into account the expressions proposed by CEB [8] in terms of stress rate:

$$
\begin{aligned}
D I F=\frac{\sigma_{t, d}}{\sigma_{t, s}}=\left(\frac{\dot{\sigma}}{\dot{\sigma}_{0}}\right)^{\delta} & \text { for } \dot{\sigma} \leq 10^{6} \mathrm{MPa} / \mathrm{s} \\
D I F=\frac{\sigma_{t, d}}{\sigma_{t, s}}=\eta\left(\frac{\dot{\sigma}}{\dot{\sigma}_{0}}\right)^{\frac{1}{3}} & \text { for } \dot{\sigma}>10^{6} \mathrm{MPa} / \mathrm{s}
\end{aligned}
$$

where: $\sigma_{\mathrm{t}, \mathrm{d}}$, is the peak dynamic tensile strength, $\sigma_{\mathrm{t}, \mathrm{s}}$, is the peak static tensile strength $\dot{\sigma}$ is the stress rate and $\dot{\sigma}_{0}$ is a constant equal to $0.1 \mathrm{MPa} / \mathrm{s}$ and has the meaning of the static stress rate; $\delta$ and $\log \eta$ are defined as:

$$
\log \eta=7.11 \delta-2.33
$$




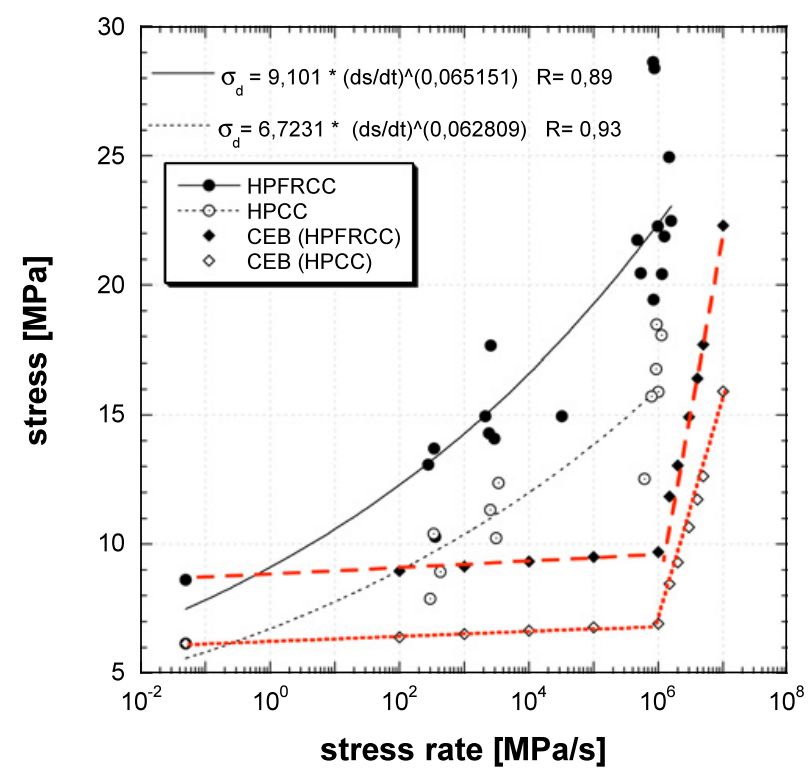

Fig. 9. Comparison of the results with CEB formulation in terms of stress vs. stress-rate.

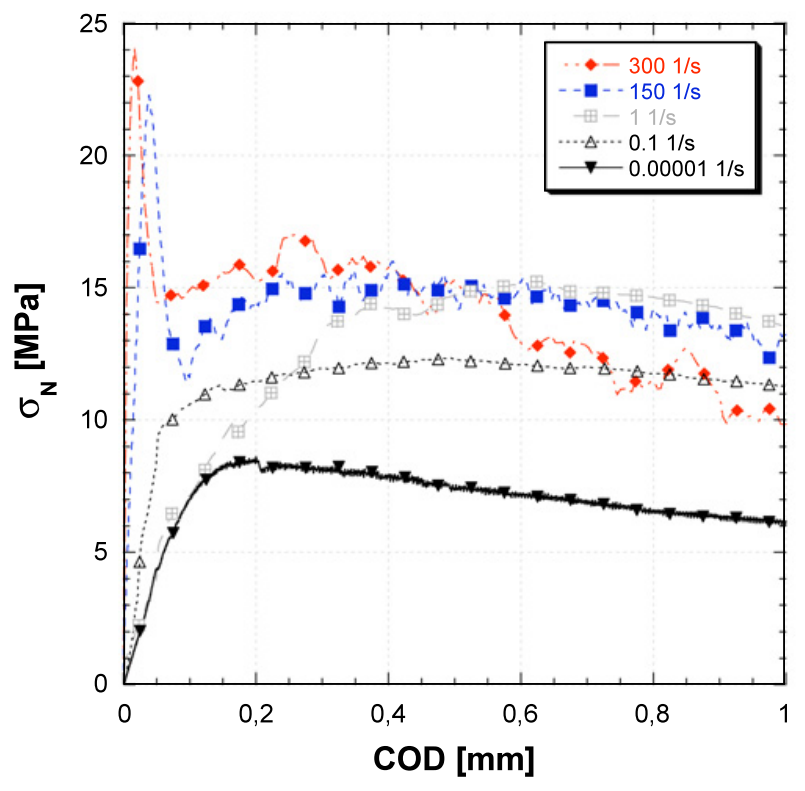

Fig. 10. Stress vs. COD at different strain rates.

$$
\delta=\frac{1}{10+\frac{f_{c}}{2}} .
$$

In figure 9 are reported all the results obtained at different stress rate and the trend-line obtained using the CEB formulation. It is clear how this relationship does not fit with experimental results, that are better described by a power function as:

$$
D I F=\frac{\sigma_{\mathrm{t}, \mathrm{d}}}{\sigma_{\mathrm{t}, \mathrm{s}}}=(\dot{\sigma})^{0.06}
$$

The strain rate influences not only the peak strength but also other parameters. Observing figure 10, where the average stress versus COD curves of the HPFRCC are

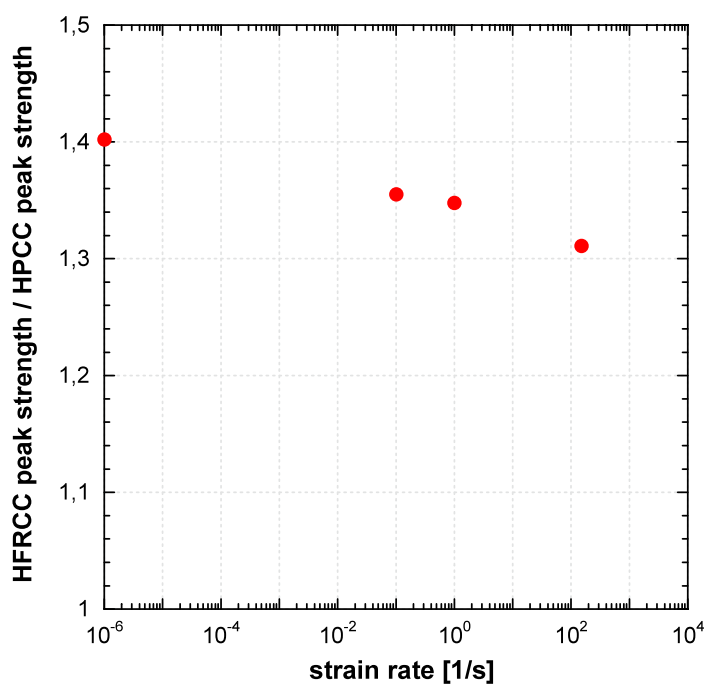

Fig. 11. Ratio between HPFRCC and HPCC peak strengths in function of the strain rate.

depicted, a remarkable increase of the post-peak stress plateau as well as the initial stiffness increase can be noted. Considering the opening of $0.4 \mathrm{~mm}$ the post-peak plateau grows from $8.5 \mathrm{MPa}$ in static condition to about $15 \mathrm{MPa}$ for higher strain rates. The last value of the stress level could be considered a dynamic threshold related to the fiber pull-out mechanism. As well described in [4], during the fracture process in a pull-out test, it is possible to divide the fibre contribution into two principal parts: the first part is that due to the debonding phase and the second part is that due to the pull-out. The pull-out mechanism for a straight fibre is a mechanism partially based on friction and it is completely activated for a relative large crack opening displacement. The plateau stress zone (for a COD between 0.2 and about $0.8 \mathrm{~mm}$ ) is surely dominated by the pull-out mechanism.

The effect of the matrix was studied in [9] where, in order to clarify the fiber contribution to peak strength increase, the ratio between HPFRCC and the HPCC peak strengths in function of the strain rate was investigated.

Figure 11 shows as, in the static field, fibers strongly influence the stable crack propagation obtaining a peak strength enhanced of about $40 \%$. By increasing the strain rate influence of the fibers is reduced. This means that the strain rate influence of the matrix, for the peak strength, is more pronounced than in static regime while the role of the fibre is of capital importance in the post-peak behaviour in which pull-out mechanism governs the failure process.

\section{Conclusions}

The dynamic behaviour of HPFRCC in tension when subjected to different strain rates was investigated.

The HPFRCC analysed shown a good fibre alignment obtained by imposing a unidirectional casting flow. As consequence, all results shown low scatter at different strain rates analysed. The material so cast, and thus characterised by a good fibre alignment, showed a very high performance compared with other cementitious composites at comparable cost. 
The strain rate sensitivity was studied by the dynamic increase factor. The DIF relationships proposed in literature for plain concrete seem to be inadequate to describe both HPFRCC and HPCC. From this first analysis, their behaviour in function of the stress rate looks better described by a power function.

The influence of the fibers was highlighted by the comparison between static and dynamic strain rate responses. By increasing the strain rate HPFRCC exhibits high values of the dynamic increase factor. The HPCC, here used as matrix, has shown higher rate sensitivity than what observed for HPFRCC.

The effect of the adjunct of the fibers implies an increase of about $40 \%$ of the peak strength in static, favouring the stable crack propagation. At high strain rates the peak strength ratio between HPFRCC and HPCC decreases to $30 \%$. The post-peak strength is almost doubled from quasi-static to dynamic regime.

The experimental results presented in this research work shown as this material can be reasonably used to improve the structural performance of tunnel lines in case of dynamic loading as explosions.

\section{Acknowledgements}

The Authors are grateful to Ing. Matteo Dotta and Ing. Daniele Forni of the DynaMat laboratory of the University of Applied Sciences of Southern Switzterland for their precious collaboration in the execution of the laboratory tests. The research was financially supported by the INTERREG IVA Program (Cross-Border
Territorial Cooperation Program for Italy and Switzerland): project ACCIDENT ID 7629770.

\section{References}

1. K. Habel, E. Denarié, E. Brühwiler, ASCE J. Str. Engg., 132, 11 (2006), 1793-1800.

2. C.B.M. Blom, T.W. Groeneweg. Shield driven tunnels in ultra high strength concrete, reduction of the tunnel lining thickness, (2007) Delft University of Technology.

3. E. Cadoni, M. Dotta, D. Forni, A. Caverzan, M. di Prisco, Structural Concrete in Switzerland, Fib-CH, 3 (2010), 12-15

4. A. Caverzan, E. Cadoni, M. di Prisco, Int. J. Imp. Engg. 45 (2012), 28-38

5. A. Caverzan, M. Colombo, M. di Prisco, High Performance Steel Fibre Reinforced Concrete: Residual Behaviour at high Temperature, Proc. of $2^{\text {nd }}$ workshop Protect2009, Hayama, Japan, (2009).

6. E. Cadoni, Rock Mech. and Rock Engg, 43(2010), 667676.

7. E. Cadoni, A. Meda, G.A. Plizzari, Mat. and Struct. 42 (2009), 1283-1294.

8. Comite' Euro-International du Béton. CEB-FIP Model Code 1990. Trowbridge, Wiltshire, UK: RedwoodBooks; 1993.

9. A. Caverzan, E. Cadoni, M. di Prisco. in High Performance Fiber Reinforced Cement Composites 6, (2011) 339-346. 